nerve centres, while the lessened oxidation occurring in sleep has a similar but much slighter effect in the course of several hours. It is probable that, in both cases, the stimulation-which gives rise in the one case to waking, and in the other to convulsions-is irnmediately caused by products of tissue-rvaste. The drowsiness which results from sitting in close rooms and churches, though partly referable to external warmth, is, in large measure, due to the presence of carbonic acid and volatile poisons from the lungs and skin.

The narcotic power of the alcohols increases as we ascend the series, as does also the number of possible isomeric compounds. There are three divisions of alcohols: (1) Primary, (2) Secondary, and (3) Tertiary, according as the carbon atom to which the hydroxyl is attached is united to one, two, or three radicals. Tertiary amyl alcohol, amylene hydrate, was recommended as a hypnotic by Schmiedeberg, and has been introduced into practice by von Mering. IIt is said to be intermediate between chloral and paraldehyde, safer than either, and not disturbing to the digestion. The next member of the series, hexyl, may yield thirty-eight alcolrols, and thirteen of these are actually known, so that the possible field for the introduction of new hypnotics is very large. The ethers, for the most part, are too volatile and their effects too transient to be of much service as hypnotics. Sulphonal : Diethyl-sulphon-dimethyl-methane appears to be one of the most effective of all the newly introduced hypnotics, and although it does not, like morphine, compel sleep, it induces sleep in a pleasant manner, and has few disagreeable after-effects, and little or no danger. Paraldehyde: Ethylic aldehyde unites with itself, their molecules combined forming paraldehyde. A greater number in combination form metaldehyde. Though simple aldehydes are intensely irritating to the mucous membranes, these polymeric forms are much less so, and paraldehyde forms a useful hypnotic, which does not depress the heart's action or give rise to subsequent discomfort. The chief objection is its unpleasant smell, which remains about the patient for many hours. Ketones: In these the group $\mathrm{CO}$ is the connecting link between two radicals. When both radicals are methyl we have acetone, which has been found in the blood of diabetics, and has been supposed to give rise to diabetic coma. By substituting other radicals for metbyl, numerous other ketones are produced, which form a long series of hypnotics. The other class of hypnotics, allied to urea, in which nitrogen may be said to form the basis, is obtained by uniting carbamic acid (CO $\mathrm{NH}_{2} \mathrm{HO}$ ) to an alkyl, so that the stimulating effect of ammonia is associated with the narcotic action of the alkyl. 'The ethyl compound, called urethane, is a useful hypnotic, though not so powerful as chloral. Unfortunately the higher members of this series are not sufticiently soluble to be active medicines.

Local Ancesthetics. - It is often convenient to annul pain in some particular region, without producing general anresthesia. For some time the effect of cold has been utilised, either by the use of ice and salt, or, more conveniently, by the evaporation of a volatile spray, such as that of anbydrous ether, or, better still, a gas liquefied by cold and pressure, such as chloride of methyl. Another plan is to employ some drug which possesses the power of producing anæesthesia, such as carbolic acid or the allied substance, paracresol. From one of the decomposition products of cocaine, ecgonine, which has no anresthetic action, cocaine itself can be built up by combination with benzoyl and methyl. In a similar way a compound of tropine, itself destitute of anæesthetic power, with benzol produces the local ancesthetic horatropine. Filehne, suspecting that the ancsthetic property resided in the benzoyl, has found that the benzoyl derivatives of several substances have a marked ancsthetic action. Unfortunately, however, many of them produce a primary irritant action, which renders them inadmissible as local anresthetics. The same is true of most of the cardiac poisons, like digitalis, which has a similar local action.

Mater Misericordie Hospital, DUblin.-.The following have been awarded prizes :-Leonard Prizes-First Medical Gold Medal: Matthew B. Savage. Second Medical Silver Medal : John McNamara. First Surgical Gold Medal: Not awarded. Second Surgical Silver Medal: Matthew $B$. Savage. A special prize (Silver Medal) was awarded to Richard Smyth for the high marks obtained by him in Medicine.

\section{SURGERY AS PRACTISED IN TURIN.1}

\section{BY PROFESSOR HUMPHRY.}

SURGERY in Turin, as represented by Signor Carle at the Ospedale Mauriziano, Signor Caponotto at the Ospedale S. Giovanni, and Signor Raymond at the Ospedale Ottalmico, is of very high order.

The Mauriziano Hospital, on the outside of the town, has. been recently built, at a cost of $£ 120,000$, with the effort to present all modern improvements. It contains 200 beds, equally divided between medical and surgical patients, who are disposed in four long wards, two for men and two for womeu; and there are several smaller wards for patients of rather higher class, who pay a certain sum, and are attended by the same medical and surgical officers as the other patients. Each of the surgical wards has at the end, shut off by folding doors from the rest of the ward, a spacious and abundantly lighted room, in which the dressing of the wounds is conducted. The bedsteads, upon castors or placed on tressels, are wheeled in and out of this room, and the wards are thus freed from the impurities attendant upon the dressing of wounds. There is also ample ward space, windows on the two sides, and the beds, each between two windows, are placed at a distance of several feet from the walls. The floors of the wards, howerer, are of pine, not very good or well laid, and already show much staining. The waterclosets and urinals, in projections from near the middles of the wards, admit of improvement. Professor Carle is the chief surgeon, having all the surgica patients under his charge, and, with a good statf of assistants, performs operations of all kinds. One patient was recovering fiom supra-pubic lithotony, and another from rhinoplasty (the nose having been formed from the forehead); one from removal of the vertebral arches at the seat of fracture, which had been attendel with some benefit; others from osteotomy, amputation of the mamma, other amputations, ¿c. The operations on women are, how. ever, those which most interest the Professor. One woman was recovering from supra-pubic removal of the uterus and ovaries, the pedicle, transfixed and girt by elastic ligature, being external; two were recuvering from removal of sarcoma of the ovary. He told ne that he had removed the uterus by the vagina for cancer eighteen times, with only two deaths. I saw this operation, the details of which give a good idea of the method pursued in conducting the operations here. Professor Carle and his assistants, dressed in long linen coats, occupied themselves at least a quarter of an hour in making their toilette, washing the hands many tirnes with hot water and soap, cutting and cleaning the nails, and soaking them in sublimate fluid ( 1 in 5000). The chamber was heated to about $80^{\circ}$ by hot air. The woman, already washed, was brought in quite naked, under chloroform, and suljected to thorough washing and injection of the vagina and surroundings with the sublimate. She was then taken into an adjoining room, in whicli operations are performed upon suppurating and septic cases. Here the carcinomatous disease of the os uteri was scraped away with Volkmann's spoons and other instruments; and, after syringing and drying, Paquelin's cautery was freely applied, the object of this being to ensure an antiseptic condition of the part. The woman, still under chloroform, was taken into the third room, a spacious and well-lighted room, where cases primarily antiseptic-for ovariotomy, laparotomy, \&c.-are operated on. After renewed sublimate washing of the surgeon's hands and patient's vagina, the os uteri having been drawn down witl vulsellum forceps, an incision was carefully made into the peritoneal cavity between the bladder and uterus, a sublimated sponge in locked forceps pushed in, the fundus of the uterus pulled out with the finger and vulsellum, the lateral connecting structures ligatured piecemeal with silk passed by means of curved needles in porte-aiguilles, and divided with scissors; and, finally, the structures between the uterus and rectum being divided also with scissors, the uterus was removed. The parts having been thoroughly washed witl the sublimate solution and sponged, the peritoneal surfaces were sutured by means of the curved neelles and the porteaiguilles, which seemed to be the most tedious ana

1 Paper read at a recent meeting of the Cambridge Medical Society. 
difficult part of the proceeding; and when all was well cleared and dried the vagina was plugged with sublimated compresses and iodoform dusted over it. I saw also an ovariotony, the same precautions being used as in the former case. The tumour was a firm, very fixed mass, as large as a child's head, which Signor Carle thought it probable he would not be able to remove; but he deemed it best to operate, as it was a source of much trouble and pain. A free incision into the abdominal cavity, extending above the umbilicus, disclosed a thick-walled cyst extensively adherent in the pelvis. It was accordingly punctured, and, the fluid having been withdrawn, was freely laid open, and some papillomaturs matter in the interior removed. The peritoneal surfaces of the sac and the abdominal walls were united by continuous suture, the edges of the sac and the skin united by sutures passed through the thick wall of the sac and the abdominal wall, the abdominal cavity carefully cleared by sublimated sponges held in long-bladed locked forceps, the sac plugged with iodoform compresses, iodoform sprinkled all over, and the whole covered with cotton-wool and bandages. Two days \&fterwards the woman was doing well.

In the Ospedale S. Giovanni, which contains 600 beds in the large long cruciform wards, with an altar at the intersecting point, and tiled floor, common on the Continent, I accompanied Signor Caponotto in his morning round, which occupies him commonly from 7 A.M. till 12, 1 , or even 2 P.M., and saw cases recovering from ovariotomy (two); removal of tongue (submental); Dupuytren's operation for artificial anus (two); laparotomy for aldominal obstruction; trephining of mastoirl process of temporal bone (two); arethrotomy for traumatic stricture; divers amputations, \&c. He usually operates at 10 A.M. He did an osteotomy for ill-set fracture of the leg in a man, similar precautions as regards washings of hands and of the patient's limb and use of the sublimate in cleaning the wound and the dressings being adopted as at the Mauriziano. Chloroform is always given in Turin in preference to ether. Signor Caponotto told me that although it was administered several times daily in that hospital, and although no particular precautions were used-indeed it was often administered by students, - a fatal result had occurred only once. In somewhat extensive observation of European hospitals, I do not know that I have ever seen better surgery, more care in antiseptic precautions, more general attention in dressing \&c., or better results, than in the hospitals of Turin, or that I have met men more equal to the various requirements of operative surgery than Signori Carle and Caponotto, and who give more time to their work. The latter informed me that he has no remuneration; the former receives 1000 francs per annum. The clinical instruction is given in the S. Giovanni by the professors. Professor Bruno lectured at length on each of two cases, a simple fracture of the leg and a common hydrocele, the greater number of the crowd of students neither seeing nor hearing anything. One could not but feel that some of them would have been better occupied in accompanying Carle or Caponotto, who were attended only by their assistants, and that this sort of division of labour was not quite satisfactory as regards teaching.

In the Ospedale Ottalmico, which is furnished with laboratory, museum, and all appropriate appllances, I saw extraction of cataract without previous iridectomy (a good circular pupil remaining), iridectomy, and other operations performed by Signor Raymond as well as I have seen them at Moorfields or elsewhere. Antiseptic precautions are here also used, the carbolic spray being employed. The hands of the operator and assistants were scrupulously washed, the sublimate water was poured over the eye, the instruments, chiefly purchased in London, were in antiseptic fluid, and iodoform, fine and carefully prepared, was dusted upon the eye after the extraction of the cataract and after some other operations.

I came to the conclusion that some of our students, after obtaining their diplomas (it is, I am sure, best to remain at the British schools till that has been done), might very advantageously spend a short time in the clear, bright, healthy, happy town of Turin, where they will have the opportunity of seeing quietly and well a greater variety of cases well treated by individual surgeons than in the more reputed and more crowded hospitals of Vienna, Berlin, or Paris. By so doing, in this and some of the other large continental towns, they might also obtain and communicate to us in England better information respecting details and general treatment and results than it was possible for me to do in my short visit this spring. Such information would be of more value than that gained at the International Congresses; at any rate, it would be a highly important supplement to them. Cambridge.

\section{CRANIO-CEREBRAL TOPOGRAPHY.}

\section{By WILLIAM ANDERSON, F.R.C.S.,} AND

\section{G. H. MAKINS, F.R.C.S.}

THE earliest of the serious attempts to demonstrate the relation of the brain convolutions to the cranium was that of Broca, ${ }^{1}$ and his researches have been followed by those of Bischoff, ${ }^{2}$ Turner, ${ }^{3}$ Féré, ${ }^{4}$ Pozzi, ${ }^{5}$ Giacomini, ${ }^{6}$ Ecker, ${ }^{7}$ Hefftler, ${ }^{8}$ Hare, ${ }^{9}$ R. W. Reid, ${ }^{10}$ Horsley, ${ }^{11}$ and Cunningham. ${ }^{12}$ The experiments of these observers may be classified into three principal groups. In the first, led by Broca, the cranial sutures were exposed, punctures were drilled at certain points in their course, and pegs or pins of wood or metal were introduced into the brain through the apertures; the more important relations of the convolutions to their bony case were thus laid down in a manner that involved no material source of fallacy beyond the variability of position of the sutures themselves in their relation to the cranium as a whole. In the second group various parts of the brain were exposed by removal of its investments, the organ having in some cases been prepared for the experiment either by injection of its vessels (Hefftler) or by freezing (Féré). Thus Turner, having removed portions of the frontal, parietal, occipital, temporal, and sphenoid bones, left a number of regions (occipital or postlambdoid, frontal or pre-coronal, antero-parietal or postcornnal, post-parietal or pre-lambdoid, and squamososphenoidal) bounded either by sutures or by arbitrary lines, and each containing certain convolutions or portions of convolutions. Hefftler prepared a series of casts of different segments of the head (anterior, superior, and posterior), then of the corresponding portions of the bony cranium and of the brain. Lastly, Cunningham, having prepared the brain by a special process in such a manner that when exposed in situ it would remain absolutely unaltered for at least twenty-four hours, removed portions of the bone on one side, leaving narrow bars of the cranial wall in the lines of the sutures and temporal ridge. Moulds were taken, and from these were prepared the valuable series of models recently exhibited at the Royal Academy of Medicine in Ireland, and at the Anatomical Society of Great Britain. The third group, the most important for the surgeon, includes the various endeavours to localise the principal brain fissures by means of certain lines and admeasurements marked upon the shaven scalp. In these regearches it was of course necessary that certain recognisable starting points for the lines or measurements in question should be defined upon the surface of the cranium and all parts of the skull that could be made available for the purpose-the glabella, the external occipital protuberance, the external angular process, the zygoma, the mastoid process, the frontal and parietal eminences, the temporal rilges, the external auditory meatus, the borders of the orbit, and the coronal and lambdoid sutures-have been utilised in one oc other of the three chief systems-that of the French school (Championnière and others), of Reid, and of Hare,-to which surgeons already owe a debt of gratitude. ${ }^{13}$

There is no doubt that by any of these carefully elaborated methods the brain points sought for could be exposed in the greater number of cases by a trephine of an inch in diameter, but there will be found in each plan certain disadvantages which render it occasionally untrustworthy.

Bulletins de la Société Anatomique, 1861

2 Die Grosshirnwindungen des Menschen. Mituchen, 1868

3 Journal of Anatomy and Physiology, vol. viii., pp. 142-36

4 Bulletins de la Sociéte Anatomique, 1875; and Archives le Physiologie, $1876 . \quad 5$ Archives Générales de Médecine, 1877. 6 Topografia della Scissura di Rolando. Torino, 1878 Archiv für Anthropologie, vol. x., 1876-78. 8 Ibid. p. 243 10 THE Journal of Anatomy and Physiology, Jan. 1884, p. 175. Tedical Lciences, Sept. 27th, 1884 . THE TAN?

13 Reid's diagram will be found in THE LANCET, vol. ii. 1884, p. 539; that of Hare in vol. i. 1838, p. 409. 